\title{
DEVELOPMENT OF COLLABORATION IN PLANNING: WHAT CAN CONSTRUCTION PROJECT MANAGEMENT LEARN FROM OTHER FIELDS?
}

\author{
Emmanuel I. Daniel ${ }^{1}$, Christine Pasquire ${ }^{2}$, Ezekiel Chinyio ${ }^{3}$, \\ David Oloke ${ }^{4}$, and Subashini Suresh ${ }^{5}$
}

\begin{abstract}
This study seeks to examine how collaboration in planning has developed in the fields of urban planning (UP), software design and lean construction and to present what construction project management can learn from these developments. A critical literature review was adopted to achieve the aim of the study. The study found that the prevailing rational or technical approach to planning is not germane to the construction industry alone. Rather, it exists in various disciplines as seen in the rational comprehensive model (RCM) used in urban planning and the waterfall process model used in software design. The research reveals that the current theory on which construction project management is based cannot provide resources, which people can utilise to develop genuine collaboration in planning among construction stakeholders. To overcome this, the study recommends that construction project management should include the concept of management-asorganising and the 'Flow' and 'Value' views which can provide resources that can be utilised by people for the smooth running of the production (construction) system as demonstrated in Scrum and the Last Planner System. This study brings new insight and opens a new opportunity on how collaboration could be achieved in construction project management using existing evidence from other fields. Additionally, the study contributes to the discussion on construction management theory that has received less attention.
\end{abstract}

\section{KEYWORDS}

Construction management theory, collaboration, construction planning, lean construction.

1 Sr. Lecturer in Constr. Mgmt., School of Arch. and Built Envir., Faculty of Sci. and Engrg., Univ. of Wolverhampton, Wulfruna Street, Wolverhampton, United Kingdom WV1 ILY, E.Daniel2@wlv.ac.uk, orcid.org/0000-0002-5675-1845

2 Prof. School of Arch. and Built Envir., Faculty of Sci. and Engrg., Nottingham Trent University UK, christine.pasquire@ntu.ac.uk, orcid.org/0000-0001-6344-2031

3 Sr. Lecturer, School of Arch. and Built Envir., Faculty of Sci. and Engrg., Univ. of Wolverhampton, United Kingdom WV1 ILY, E.chinyio@wlv.ac.uk, orcid.org/0000-0001-8448-5671

4 Built Environment Engr, School of Arch. and Built Envir., Faculty of Sci. and Engrg., Univ. of Wolverhampton, UK WV1 ILY, D.A.Oloke@wlv.ack, orcid.org/0000-0002-0730-7262

5 Reader, School of Arch. and Built Envir., Faculty of Sci. and Engrg., Univ. of Wolverhampton, UK WV1 ILY, S.Subashini@wlv.ac.uk, orcid.org/0000-0001-5266-128X 


\section{INTRODUCTION}

The current state of planning in the construction industry has been criticised. Faniran et al. (1998) observe that the current focus of construction planning is on forecasting project performance based on specified milestones with less regard to the process used to achieve the plan. Planned tasks are usually pushed to conform to predetermined milestones due to lack of collaboration between those involved in developing the plan. According to Atkins et al. (2008), construction planning tends to separate team roles and create walls of barriers between stakeholders on the project, which contributes to time and cost overruns. However, the absence of adequate collaboration in planning is not peculiar to construction project management, as it has also been observed in urban planning and software design (Janssen-Janssen and Lloyd 2018; Highsmith and Cockburn 2011). According to Highsmith and Cockburn (2001), at first, software design tends to focus on how to conform design to plan, which in reality is not attainable and adds to time and cost overruns. On the other hand, Susskind et al. (2000) observed that the rational comprehensive model approach that dominated urban planning in the 1960s in North America also imposed planning decisions on communities without their input. However, current evidence suggests that these two fields are now adopting more collaborative approaches in their planning and design processes (Moroni 2019; Robertson and Simonsen 2012; Rising and Janoff 2000; Rittel and Webber 1970). Additionally, from a lean construction perspective, the Last Planner System has been identified as a lean construction technique that supports the development of collaborative relationship among different participants in a construction project (Ballard and Tommelein 2016). Given this, the study sought to answer these research questions: Q1: How has collaboration in planning evolved in the fields of urban planning, software design and lean construction? Q2: What can construction project management learn from this evolution?

Despite the construction industry's reluctance to change and innovate, some attempts have been made to improve construction management through the diffusion of knowledge from other fields (Keraminiyage 2005; Faniran et al. 1998; Egan 1998). For instance, Koskela (1992) had researched into the adoption of lean production principles that are used in the manufacturing sector; Wehbe and Hamzeh (2013) studied the use of Failure Mode and Effect Analysis (FMAE), a military-based technique, to improve look-ahead planning in construction; and Li et al. (2008) investigated the use of the IKEA model, a manufacturing-based approach, to improve construction process management. This means construction management is adapting or willing to adapt knowledge from other sectors.

\section{LITERATURE REVIEW}

\section{Current Construction Planning Approach}

Planning is an essential undertaking in construction project management. It is no surprise, that construction project managers spend a third of their time in planning and coordination (Mustapha and Langford 1990). However, Johansen (1995) observes that construction and project managers complain of lack of time to engage in detailed planning, which heightens the uncertainty in the construction process. Uncertainty and variability are common features associated with construction planning. Laufer et al. (1992) observe that uncertainty is an integral characteristic of construction, and further argues that higher uncertainty makes planning less effective. 
Tommelein et al. (1999) show the effect of variability in the performance of construction trades through simulation, while Alarcon and Ashley (1999) reveal the impact of uncertainty on construction planning and cost. Despite these empirical shreds of evidence, current construction planners and managers seem not to acknowledge this in the planning process. Most times, plans are too detailed, done too early, and too rigid with less account for the inherent uncertainty in the construction environment (Daniel 2017). To compound this, it has been observed that construction planners tend to ignore the inherent uncertainty in the construction process while planning (Ballard and Howell 2003). Johansen (1995) presents two opposing views on the concept of uncertainty in construction; the hard and soft approaches. The study argues that the hard approach school of thought centres the success of a construction programme on a rigid production of a plan that is based on a network analysis and monitoring of the critical path. The soft approach believes that the rigid approach cannot yield the intended result because of the inherent uncertainty and complexity in the project environment. Thus, the soft approach is deficient in current planning practice in the industry (Daniel 2017; Johansen 1995).

\section{RESEARCH METHOD}

A qualitative literature review approach was used to understand the development of collaboration in planning in the fields of urban planning, software design and lean construction, and present the implications for construction planning and project management theory and practice in general. Grant and Booth (2009) observed that a critical literature review allows for a synthesis of materials from different sources, facilitates a degree of analysis and conceptual innovations, provides conceptual contributions to an existing body of knowledge and provides a launch pad for new research. The critical review approach provides a useful evaluation of the pieces of literature sampled to provide a conceptual contribution to construction project management practice and theory. Grant and Booth (2009) further observed that a critical literature review allows researchers to contribute to the existing body of knowledge in a given field. A critical literature review was thus adopted to address the research questions proposed. The paper is structured thus: (1) Explores the concept of collaboration in planning in the critical path method (2) analyses the development of collaboration in planning in urban and regional planning (3) analyses the evolvement of collaboration in planning in software design (4) presents the concept of collaboration in planning from lean construction perspective (5) explore relevant theory and theorist in urban planning, software design and lean construction. In sections 6 and 7, the implication for construction project management and theory are evaluated and discussed.

\section{COLLABORATION IN PLANNING: THE CRITICAL PATH METHOD (CPM)}

The CPM approach develops construction programmes right from pre-construction to project commissioning using activity breakdown structure to generate a list of activities. An expert construction planner usually does it (Koskela et al. 2014; Senior 2007). Koskela et al. (2014) assert that the CPM has been hailed as one of the most important innovations in construction management in the 20th Century. It is advocated for by clients and construction professionals and taught on most construction management courses (Senior 2007). Despite its popularity, (Happin 1993) observed that it is less used by field workers while managing construction processes on site. Senior (2007) observes that its low use by site workers is because of its unrealistic nature due to the non-involvement of those doing the work (the site workers) in the planning process. The focus of the CPM includes, but 
not limited to; what is the start date? and what is the finish date? These are usually arrived at based on the planner's experience. Docherty (1972) observes that the programmes developed based on the CPM are rarely used, while work execution is usually managed by short term planning by site workers. This suggests that the use of CPM in construction does not develop collaborative relationships.

\section{COLLABORATION IN PLANNING: URBAN PLANNING}

The complexity and diversity in urban and regional planning are among the rationale for a collaborative approach in planning (Healey 2003). Brand and Gaffikin (2007) assert that collaborative planning is an interactive and participatory approach that enables a community to define their social space. However, the approach to planning in North America at the end of World War II was based on the Rational Comprehensive Model (RCM) or technocratic planning (Janssen-Jansen, and Lloyd 2018) which does not support community participation. This approach views planning as a technical and scientific discipline, which can only be performed by experts and without any form of input from the community (Moroni 2019; Susskind et al. 2000). Because of this, the government of the USA through the planners imposed planning decisions on communities without stakeholders' participation.

However, in the 1960s the RCM was greatly challenged because of its many shortfalls, especially, the lack of representation of stakeholders' views in the decision making processes (Janssen-Jansen and Lloyd 2018; Rittel and Webber 1973). Banfield (1955) observed that the RCM model is based on five basic steps: end reduction and elaboration, developing cause for action, comparatively analysis consequence, choosing from alternative and implementing chosen alternative. It is worth noting that these steps are based on scientific analysis and lack any form of collaborative input. Thus, the model was heavily criticised. A fundamental contention is in the area of individual and collective rationality (Stiftel 2000). The criticism and failure of the RCM led to the development of other models that allow for public participation in planning and decision-making processes such as advocacy planning and collaborative planning models. Figure 1 shows the progression from the RCM to a collaborative planning $(\mathrm{CP})$ model. The $(\mathrm{CP})$ model is a step ahead of advocacy planning, however, both are based on a singular goal; that is, the collective participation of stakeholders in the planning and decision-making process (Stiftel 2000).

Figure 1: Development of collaboration in urban planning

The CP model is a consensus-based planning approach that brings all the stakeholders together with the sole aim of collectively devising the best means of attaining the intended goal (Moroni 2019). The major target of CP is to create a platform for incorporating stakeholders' ideas before decisions are made. Although this approach to planning has also been criticised, that it tends to take away power from those it has been vested (Hearley 2003; Allmendiger and Mark 2002); there are also cost and time implication for collaboration in planning (McCaffrey et al.1995); and that people tend to weigh the benefits and challenges of collaboration in planning before going into it (Rayle and Zegras 
2013). However, researchers have long-established that the participation of the public or stakeholders in the planning process does not only give legitimacy to the planned task but also motivates these stakeholders to be fully committed to the tasks (Moroni 2019; Gunton et al. 2003).

\section{COLLABORATION IN PLANNING: SOFTWARE DESIGN}

The term 'Software engineering or design' came into limelight in the late 1950's and 1960's. Specifically, it is believed to have become an official profession following the NATO Science Committee conference held in Germany in 1969 (Rayl 2008). Highsmith and Cockburn (2001) argued that the traditional approach used in software design tends to focus on how to conform design to plan, which in reality is not achievable and contributes to time and cost overruns. To overcome these setbacks, various planning models have been adopted in the software development process: i.e. waterfall and agile.

The waterfall process model is the oldest classical model used in the planning of software engineering design. According to Jaitly (2014), the traditional waterfall software programming or planning approach focuses on techniques rather than people and the customer. The model enables customers to get a defined process at the beginning of product development (Rising and Janoff, 2000), but in reality, it is usually impossible to obtain all the requirements for the software development at the onset of a project due to external factors that could arise from the environment (Highsmith and Cockburn 2001). The shortfall in the waterfall model led to the development of the Agile software development process.

The Agile software development process shows a clear departure from the traditional classical approach to software development. Its movement was initiated to develop a faster, cheaper, and better solution to overcome the problems associated with the traditional approach (Dyba and Dingsoyr 2008), and as well overcome the traditionalist rigid approach to the design process (Dyba 2000). A "traditionalist" believes that through comprehensive planning based on the knowledge of the planner, the planning process could be made efficient without considering the variability in the environment (Boehm 2002). In contrast to this, the agile process model sets to overcome the variability in the process by depending on people rather than on techniques alone. The unique feature of the agile process is that it develops around the customer and users (Jailty, 2014; Robertson and Simonsen 2012). Ericksson et al. (2005) p89 defined it in relations to software development as: "agility means to strip away as much of the heaviness commonly associated with the traditional software-development methodologies, as possible to promote quick response to changing environments, changes in user requirements and accelerated project deadline and the like".

This shows that the agile process model considers the variability and uncertainty inherent in the design process and allows for the full involvement of the team on the project, suggesting that it has the potential of developing collaborative relationships among the stakeholders. The concept of stakeholder involvement or customer collaboration as advocated in software design connotes that sponsors, users, and developers are all operating as a team (Robertson and Simonsen 2012; Highsmith and Cockburn 2001). The four key features of the agile methodology, which have been termed as "Agile Manifesto" by Highsmith and Cockburn (2001), include; more focus on individual and interactions over process and tools, feasible software development over comprehensive planning, customer collaboration over contract and negotiation and responding to changing environments over following a plan rigidly. The Agile process 
model uses methods such as Scrum, Extreme programming, Crystal methodologies, Dynamic Software Development Methodology (DSDM), Adaptive software development, and feature-driven development among others (Dyba and Dingsoyr 2008). Koskela and Howell (2002) perceive that the theory behind the Scrum approach is based on management-as-organising, language action perspective and theory of flow and value.

\section{REVIEW OF RELEVANT THEORIES: EXPLORATION OF RELEVANT THEORY AND Theorist In URban Planning, SOFTWARE Design AND Lean}

Various theorists have challenged the scientific view or approach to urban planning, software design and construction project management. Notable among these are Rittel and Webber (1973) who challenged the rational comprehensive model approach to planning; Sanders and Stappers (2008), Robertson and Simonsen (2012) who advocated the need of co-creation and participatory design in lean construction. Koskela (1992) introduced the Transformation, Value and Flow theory that challenges the construction industry to add "Value" and "Flow" to the "Transformation" view that currently dominates construction management; and Ballard and Howell introduced the Last Planner System (LPS) (Ballard and Tommelein 2016; Daniel et al. 2015) that supports collaboration among those doing the work. One of the principles of the LPS is to allow the people doing the work to do the plan (Ballard and Tommelein 2016).

In urban planning, Rittel and Webber (1973) observed that planners were not able to satisfy the customer because they were not delivering what the customer wants through the scientific approach. This is because the societal problem the planner deals with is not always well defined in the perspective of a scientific problem; hence, these are termed 'wicked problems'. However, it was recommended that the system approach that allows various actors to collaborate would be able to solve the 'wicked problem (Rittel and Webber 1973b). Participatory design and co-creation are used in software design. This could be through workshop, prototyping or use of a model to engage with the users to develop a future state (Robertson and Simonsen, 2012). It has been observed that the approach supports reflection and mutual learning. However, Sanders and Stappers (2008) assert that the concept of co-design could be a threat to top managers and will require creativity from participants to make it work. This implies that those who will be involved in a collaborative planning meeting should have some level of knowledge of the subject matter in order to make a valid contribution.

\section{REVIEW OF RELEVANT THEORIES: EXPLORATION OF MANAGEMENT-AS- Planning and Management-AS-ORganising Theory}

The management-as-planning (MAP) theory dominates the current approach used in construction planning. This theory advocates that a project consists of two parts; "the managerial part" (the planner who does the planning) and "the effector part" (the field workers) who are responsible for translating the plan into action (Johnston and Brennan, 1996). Koskela and Howell, (2002) observed that the management-as-planning theory advocates for plan centralisation, revision of plan and then implementation. This implies that in this approach, field workers are not involved in the planning at the beginning although they could be during the revision phase. To overcome this, the management-asorganising (MAO) view is presented (Johnston and Brennan, 1996). In this approach, it is believed that each sub-unit in the system can plan, sense and act, thus, the planning decision should not be left with "the managerial part" alone. In construction, this approach 
supports the inclusion of the supply chain in the planning process as demonstrated in the LPS.

\section{LEARNing FOR Construction Project Management}

The developments (changes) in the field of UP and in software development in the approach towards planning should serve as a great learning point for construction project management practice. For instance, the RCM that previously formed the basis of planning decisions in UP has been established to form the basis of the CPM planning practice in the construction industry. However, due to the negative impact of the RCM approach on planning decisions, the urban and regional planning profession opted out of using it and now advocates for collaborative planning models (Stiftel 2000; Rittel and Webber 1973). This suggests that the RCM that views planning as a scientific discipline and claims that the knowledge needed for planning is with the expert planner alone, is ineffective and needs to be avoided. Given this, the construction management approach should also move away from the current practice where planning decisions are left to the construction planner or the planning engineer alone. The knowledge needed for planning is not in the possession of a single individual but rather dispersed among many people (Rittel and Webber 1973; Hayek 1945). However, this reality is yet to be fully accepted in construction project management. Leaving the planning decision to the expert planner alone means the planned project duration may be based on incomplete knowledge.

Johansen and Greenwood, (1999) observed that relying on the knowledge of the planner alone to decide on activity durations is always a guesswork, which contributes to the high level of uncertainty in construction schedules. It can be argued that the failure of construction project management concerning planning is due to its focus on rigid planning techniques than on adopting planning processes that are more collaborative and efficient. Cohenca et al. (1989) reiterated that, even with the emergence of various planning techniques, construction planning has not been able to improve on the level of its efficiency. The change experienced in UP and software development about improved planning practice could be attributed to the inclusion of people and processes in the planning and decision-making system, rather than rigidly focusing on planning techniques alone. For instance, Faniran et al. (1998) suggested that construction project management should improve the efficiency of the industry by focusing on improving the construction planning process instead of holding on to rigid planning techniques alone. Furthermore, the incorporation of human elements in UP (collaborative planning model) and software development (Agile process models) has contributed immensely to the development of collaborative approaches in these fields, which construction practice can adopt.

The importance of the human (social), as opposed to the technical element alone in construction project management, has been emphasised (Brasen et al. 2003). This approach was demonstrated in the planning and allocation of space in UP, in software development and the LPS. For example, in the Scrum approach, the client and all the other stakeholders in the software development process are fully involved through prototyping, workshops and seen as direct customers to each other (Robertson and Simonsen 2012). This improves the level of conversation and commitment to the task, thus improving the quality of the final product (Jannof and Rising 2000). As seen in this approach, the focus is not on a single individual in the team, but rather the teams are selforganised to deliver the task. This implies that construction management should create an environment that could empower all stakeholders to contribute, especially in the 
construction planning process. The need to adopt a collaborative approach in construction planning is now more crucial, considering the accuracy associated with construction planning (Faniran et al. 1998; Johansen 1996). Gonzalez, (2008) observed that the failure of construction planning does not only contribute to poor decisions but also the failure in construction project management approaches. Because variability and uncertainty are inescapable in construction planning and project environment in general, the goal should not be on how to stop the change using rigid and long-term plans. Rather, construction project management must come to terms with the current realities in the project environment in order to improve production.

\section{Contribution to Construction Project Management Theory}

The evaluation of the development of collaboration in planning in other fields is crucial as various construction management scientists argue that there is no uniform theory guiding the construction management practice (Koskela 2000; Harris 1998; Halpin 1993). For instance, Halpin (1993) opines that if there is any theory for construction management, such theory is still in hiding. In addition, Koskela, (2000a) argued that the current construction project management approach is based on the theory of production that emerged from economics. Koskela, therefore, postulated that the concept of Transformation, Flow, and Value (TFV) be adopted as the fundamental theory to build construction project management upon (Koskela 1992).

In reality, the current practice of construction project management is only limited to the 'transformation view' (Sacks et al. 2016; Koskela 1992) which entails the conversion of input into an output. The RCM used in the UP planning process could be said to be based on the transformation view theory. Similarly, the Waterfall process model used in software development and the traditional approach to planning in construction can be said to be based on CPM. This is so, since the tenets of the 'transformation view' is on how tasks would be executed effectively following a defined or structured process without considering the influence of external phenomena. Koskela (1992) argued that the focus of the transformation view is on task management. Though good, it cannot manage variability and meet customer requirements. This means that the application of transformation view alone in construction project management and planning cannot mitigate variability in the construction process.

However, Koskela (2000) proposed that the inclusion of the flow and value views in construction project management would no doubt help in overcoming the current deficiency associated with the transformation view. The concept of flow and value generation from the customer's perspective has been in production for decades (Shewhart 1931; Gilbreth and Gilbreth 1922); but construction project management is yet to fully embrace this reality. The development of collaboration in planning in these fields of knowledge has shown that the incorporation of the concept of flow and value to the transformation view could support better collaboration in the construction management process (Highsmith and Cockburn 2001; Stiftel 2000). For example, the move from the waterfall process model (transformation only view) in software development to the use of Scrum and Extreme programming (Agile process model-based) is due to the inclusion of the flow and value generation theory concept.

Koskela and Howell (2002) argued that the decision-making process that supports value generation should be decentralised and all the stakeholders in the development process should be given a clear say. They suggest that project planning and management should be viewed as both management-as-organising and management-as-planning rather 
than as management-as-planning alone as contained in the transformation view. This shows the level of improvement that can be achieved in construction project management when built on sound theories; such as the inclusion of the flow and value theory. The successful application of this broadened approach in software development implies its application in construction project management is realistic and could be beneficial. More importantly, this theoretical concept of transformation and flow is now being applied in the LPS (Daniel et al. 2019; Koskela 2000a), with significant impacts on managing project production in construction. Koskela (2000a) argued that the application of sound theory to construction project management would improve performance while its absence will support poor performance. This suggests that more focus should be given to theory in construction management. However, Seymour et al. (1997) observed that researches in construction project management tend to pay less attention to the interpretivism approach that is rigorous enough to develop sound theory.

\section{CONCLUSIONS}

The study presented was undertaken to evaluate the development of collaboration in planning by drawing lessons from the fields of urban planning, software design and lean construction in order to identify what construction project management can learn. The study found that the prevailing rational or technical approach to planning is not germane to the construction industry alone. Rather, it exists in various disciplines as seen in the RCM being used in urban planning and the waterfall process model being used in software design. This means that the construction industry should not be outrightly blamed for its current inadequate practice but should be supported to move up from its position that has less apparatus to support collaboration in planning and the execution of work. The successful adoption of collaborative approaches in other knowledge areas shows that the construction industry could move from its current technical approach to a more social approach that encourages collaboration.

The investigation found that the current approach of planning in construction project management is limited to the 'transformation view theory' as unveiled in the RCM, CPM, and the waterfall process models. Its focus is on how tasks would be executed effectively following a defined or structured process without considering the influence of external phenomena. This approach alone cannot manage variability, meet customer requirements and provide resources that people can utilise to develop collaboration in construction project management. However, the LPS and the Scrum methods integrate the 'transformation' 'Flow' and 'Value' view theory; and can provide resources that can be utilised to support collaboration and workflow among those doing the work. Thus, the study concludes that the current theory of construction project management, which is essentially 'management-as-planning' (the Transformation view) alone, cannot provide adequate resources that can be used to develop collaboration in construction planning. To overcome this shortcoming, the study recommends that construction project management should include the concept of management-as-organising and the 'Flow' and 'Value' view which can provide resources that people can utilise for the smooth running of the production (construction) system as demonstrated in Scrum and the Last Planner System.

This study brings new insight and opens a new debate on how collaboration could develop in construction project management by using existing evidence from other fields. The study also contributes to the discussion on construction project management theory. Future studies of the subject matter could explore empirically, using multiple case studies 
to understand if the current relationships in construction planning are adversarial and confirm if planning is still at the rudimentary level in construction project management.

\section{REFERENCES}

Alarcón, L. F. and Ashley, D. B. 1999. "Playing Games: Evaluating the Impact of Lean Production Strategies on Project Cost and Schedule", Proc. 7th Ann. Conf. of Intl. Group for Lean Const, University of California, Berkeley, USA, 26-28 July.

Allmendinger, P and Mark, T. 2002. Planning Futures: New Directions for Planning Theory. Routledge, London.

Atkin, B., Borgbrant, J. and Josephson, P.E. 2008. Construction Process Improvement. John Wiley \& Sons, London

Ballard, G. and Tommelein, I. 2016. Current Process Benchmark for the Last Planner. Project Production Laboratory, Univ. of California, Berkeley.

Ballard, G. and Howell, G.A. 2003. "An Update on Last Planner". In Proc. of the 11th Ann. Conf. of the Intl. Group for Lean Const. Virginia, USA, July 2003.

Banfield, E.C. 1959. "Ends and Means in Planning”. Int. Social Science J., 11 (3), 361368.

Boehm, B. 2002. "Get Ready for Agile Methods with Care". Comp., 35(1), 64-69.

Brand, R. and Gaffikin, F. 2007. "Collaborative planning in an Uncollaborative world". Planning theory, 6(3), 282-313.

Bresnen, M., Edelman, L., Newell, S., Scarbrough, H. and Swan, J. 2003. "Social Practices and the Management of Knowledge in Project Environments". International Journal of Project Management, 21 (3), 157-166.

Cohenca, D., Laufer, A. and Ledbetter, W.B. 1989. "Factors Affecting Construction Planning Efforts". Journal of Constr. Engr. and Management, 115 (1), 70-89.

Daniel, E.I., Pasquire, C. and Dickens, G. 2019. "Development of Approach to Support Construction Stakeholders in Implementation of the Last Planner System". Journal of Management in Engineering, 35(5), 04019018-1 - 04019018-16

Daniel, E., 2017. "Exploratory study into the use of Last Planner ${ }^{\circledR}$ System and collaborative planning for construction process improvement." $\mathrm{PhD}$ dissertation, Nottingham Trent University, Nottingham, United Kingdom

Daniel, E.I., Pasquire, C. and Dickens, G. 2015. "Exploring the implementation of the Last Planner ${ }^{\circledR}$ System through IGLC community: Twenty one Years of Experience". In: Seppänen, O., González, V.A. and Arroyo, P. (eds.). Proc. 23rd Annual Conf. of the Int. Group for Lean Const., Perth, Australia, 29-31 Jul., pp.153-162

Dybå, T. and Dingsøyr, T. 2008. "Empirical Studies of Agile Software Development: A Systematic Review". Infor and Software Technology, 50 (9-10), 833-859.

Egan, J. 1998. The Egan Report-Rethinking Construction. Report of the Construction Industry Task Force to the Deputy Prime Minister. HMS Office, London, UK.

Faniran, O.O., Oluwoye, J.O. and Lenard, D.J. 1998. "Interactions between construction planning and influence factors". Jour. of Constr. Engr. and Manag. 124 (4), 245-256.

Gilbreth, F. B. and Gilbreth, L.M. 1922. "Process Charts and their Place in Management". Mechanical Engineering, 70(1) 38-41

Gonzalez, V., Alarcón, L. F. and Mundaca, F. 2008. "Investigating the Relationship between Planning Reliability and Project Performance". Production Planning and Control, 19(5), 461-474.

Grant, M.J. and Booth, A. 2009. "A Typology of Reviews: An Analysis of 14 Review types and Associated Methodologies". Health Inf. \& Libraries Jnl, 26 (2), 91-108. 
Gunton, T. I, Day, J C. Williams, P. W. 2003. "The Role of Collaborative Planning in Environmental Management: The North American experience". Environments: Journal of interdisciplinary studies, (31) 2, 1-5

Halpin, D.W. 1993. "Process-based Research to Meet the International Challenge". Journal of construction engineering and management, 119 (3), 415-425.

Harris, C. 1998. "Why Research without Theory is not Research: a Reply to Seymour, Crook and Rooke". Constr. Mgmt and Economics, 16 (1), 113-116.

Hayek, F. A. 1945. "The use of Knowledge in Society”. The American economic review, 35(4), 519-530

Healey, P. 2003. "Collaborative Planning in Perspective. Planng.Theory, 2(2), 101-123.

Highsmith, J. and Cockburn, A. 2001. "Agile Software Development: The Business of Innovation". Computer, 34 (9), 120-127.

Jaitly, S. 2014. Implementation Of Quality in an Agile Software Development Environment to Quicken Delivery of Software based on Customer Requirements. Doctoral dissertation, California State University, California, USA

Janssen-Jansen, L. and Lloyd, G. 2018. "Provenance, Ideology and the Public interest in planning. The Routledge Handbook of Institutions and Planning in Action: Routledge, London; 228-241

Johansen, E., and Greenwood, D. (1999). "Hard, Soft or Lean? Planning in Medium Sized Construction Projects". In: Hughes W, (Ed.), 15th Annual ARCOM Conference, Liverpool John Moores University UK, 15 -17 September. 2, 385-394

Johnston, R.B. \& Brennan, M. 1996. Planning or Organizing: the Implications of Theories of Activity for Management of Operations. Omega, International Journal Of Management Science, 24, (4), 367-384.

Johnston, R.B. 1995. "Making Manufacturing Practices Tacit: a Case Study of Computer Aided Production Management and Lean Production". Journal of Operational Research Society. 46(10), 1174-1183

Keraminiyage, K.P. Amaratunga, R.D.G. and Haigh, R.P. 2005, "UK Construction Processes and IT Adoptability: Learning from other Industries", In: 11th Joint CIB International Symposium - Combining Forces, Helsinki, Finland 13-16 June 2005.

Koskela, L J and Howell, G 2002. "The Underlying Theory of Project Management is Obsolete". In: Dennis, P. S., David, I. C., Jeffery, K.P. (eds.). Proceedings of the PMI Research Conference, Seattle, Washington, 293-302

Koskela, L. 1992. Application of the New Production Philosophy to Construction. Technical Report No. 72, Centre for Integrated Facility Engineering, Department of Civil Engineering. Stanford, CA: Stanford University.

Koskela, L. 2000. An Exploration Towards a Production Theory and its Application to Construction. PhD Dissertation, Helsinki University of Technology, HelsinkiFinland.

Koskela, L. (1999). "We Need a Theory of Construction." Berkeley-Stanford CE\&M Workshop: Defining a Research Agenda for AEC Process/Product Development in 2000 and Beyond, University of Stanford, CA. $26-28$ Aug.

Koskela, L. and Ballard, G 2006. "Should Project Management be Based on Theories of Economics or Production"?' Building Research and Inf, 34 (2), 154-163.

Koskela, L., Howell, G., Pikas, E. \& Dave, B. 2014. "If CPM is so Bad, Why have we been using it so Long". In: Kalsaas, B.T., Koskela, L. \& Saurin, T.A. (eds). Proc. 22nd Ann Conf. of the Intl Group for Lean Const. Oslo, Norway, 25-27 Jun. 27-37 
Laufer, A., Howell, G.A. and Rosenfeld, Y. 1992. "Three Modes of Short-term Construction Planning". Const. Mgt and Economics, 10 (3), 249-262.

Li, H., Guo, H., Skibniewski, M. J. and Skitmore, M. 2008. "Using the IKEA model and virtual prototyping technology to improve construction process management". Construction Management and Economics, 26 (9), 991-1000.

McCaffrey, D.P., Faerman, S.R. and Hart, D.W. 1995. The Appeal and Difficulties of Participative Systems, Organisation Science, 6 (6), 603-627.

Moroni, S., 2019. Critically Reconsidering Orthodox Ideas: Planning as Teleocratic Intervention and Planning as a Rational Decision Method. Planning Theory \& Practice, 20(3), 323-338.

Mustapha, F.H. and Langford, D., 1990, March. What skills do effective site managers bring to their work. In Proceedings of the CIB W-90 Conference, 6th March, University of Technology Sydney, Sydney, Australia, 346-357.

Rayle, L. and Zegras, C., 2013. The Emergence of Inter-municipal Collaboration: Evidence from Metropolitan Planning in Portugal. European Planning Studies, 21(6), 867-889.

Rayl, A.J.S. 2008. "NASA Engineers and Scientists-transforming Dreams into Reality". [Online] Available at: http://www.nasa.gov/index.html. [Retrieved 23 May 2020].

Rittel, H.W. and Webber, M.M. 1973. "Dilemmas in a General Theory of Planning". Policy sciences, 4(2), 155-169.

Robertson, T. and Simonsen, J., 2012. "Challenges and Opportunities in Contemporary Participatory Design”. Design Issues, 28(3), 3-9.

Sacks, R., Seppänen, O., Priven, V. and Savosnick, J. 2017. "Construction flow index: a metric of production flow quality in construction". Constr. Mgt and Eco35 (1-2), 45-63.

Sanders, E.B.N. and Stappers, P.J. 2008. "Co-creation and the New Landscapes of Design". Co-design, 4(1), 5-18.

Senior, B.A. 2007. "Implications of Action Theories to Lean Construction Applications". In:, Pasquire, C.L, . \& Tzortzopoulos, P. (eds). Proc. 15th Ann Conf. of the Int. Group for Lean Const. East Lansing, Michigan, USA, 18-20 Jul 407-416

Shewhart, W.A. 1931. Economic Control of Quality of Manufactured Product. Van Nostrand, New York, USA.

Stiftel, B. 2000. Planning Theory. The National AICP Examination Preparation Course Guidebook. American Institute of Certified Planners, Washington, DC, USA.

Susskind, L., Mieke van der, W. and Armand, C. 2000. Mediating Land use Disputes: Pros and Cons. Lincoln Institute of Land Policy, Cambridge, UK.

Seymour, D., Crook, D. and Rooke, J. 1997. "The role of Theory in Construction Management: a Call for Debate. Constr. Mgmt. \& Econo. 15 (1), 117-119.

Tommelein, I.D., Riley, D.R. and Howell, G.A., 1999. "Parade Game: Impact of work Flow Variability on Trade Performance". J of Const Eng. \& Mgt, 125 (5) p304-310.

Tranfield, D., Denyer, D. and Smart, P. 2003. "Towards a Methodology for Developing Evidence-informed Management Knowledge by Means of Systematic review". British journal of management, 14(3), 207-222.

Trauner, T.J. 1993. Managing the Construction Project: a Practical Guide for the Project Manager. John Wiley \& Sons Incorporated, Chichester, UK.

Wehbe, F.A. and Hamzeh, F.R. 2013. "Failure Mode and Effect Analysis as a Tool for Risk Management in Construction Planning. Proceedings of 21st Ann Conf. of the Intel Group for Lean Const. Fortaleza, Brazil, 481-490. 